RESEARCH PAPER

\title{
Smoker and ex-smoker reactions to cigarettes claiming reduced risk
}

\author{
S Shiffman, J L Pillitteri, S L Burton, M E Di Marino
}

Tobacco Control 2004;13:78-84. doi: 10.1136/tc.2003.005272

See end of article for authors' affiliations

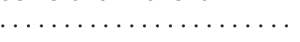

Correspondence to: Saul Shiffman, PhD, Pinney Associates, 201 North Craig Street, Suite 320, Pittsburgh, PA 15213, USA; shiffman@ pinneyassociates.com

Received 15 July 2003 Accepted 2 October 2003
Context: The tobacco industry is introducing modified tobacco products claiming to reduce the risk of smoking (potential reduced exposure products, PREPs). If PREPs are perceived as safe, they may deter smokers from quitting and encourage re-initiation by smokers who have quit.

Objective: To assess smokers' and ex-smokers' perceptions of PREPs and the impact of PREP claims on interest in quitting (among smokers) or in resuming smoking (ex-smokers).

Design: A random-digit-dialled survey of US smokers and ex-smokers. We used Eclipse, a modified PREP cigarette, as an exemplar PREP. During the survey, the interviewer read risk reduction claims made for Eclipse by its manufacturer, assessing smokers' interest in quitting before and after the exposure.

Participants: 1000 current cigarette smokers and 499 ex-smokers (300 quit within the last two years), over 18 years old.

Main outcome measures: Perception of risk reduction from Eclipse; interest in using Eclipse; smokers' interest in quitting was assessed using a stage of change approach (pre- and post-exposure to claims).

Results: $91 \%$ of smokers thought Eclipse was safer than regular cigarettes. $24 \%$ believed Eclipse was completely safe. $57.4 \%$ of smokers were interested in using Eclipse; interest was greatest among smokers who were contemplating quitting. Exposure to Eclipse's claims was followed by reduced interest in quitting. Among all ex-smokers, interest in Eclipse was $6.2 \%$, but interest was $15.2 \%$ among young adults (18-25 years) who had stopped smoking within two years.

Conclusions: There is substantial risk that smokers will overinterpret reduced risk claims made for modified tobacco products. PREPs appeal to smokers who are contemplating quitting and exposure to reduced risk product claims appears to reduce smokers' readiness to quit. PREPs also appealed to young adults who had recently stopped smoking. Thus, reduced risk tobacco product claims can undermine adult cessation and youth prevention, possibly resulting in increased harm even if the products are less toxic.
$\mathrm{S}$ moking attributable morbidity and mortality has reached epidemic proportions. In the USA, 46.2 million adults smoke and smoking kills 440000 people annually $^{12}$; globally, there are 1.1 billion smokers, and 4.9 million smokers are killed annually. ${ }^{3}$ Tobacco control efforts have focused on preventing uptake of smoking and promoting cessation among those who already smoke.

Smokers concerned about their health are interested in either stopping smoking entirely or in reducing the risks associated with continued smoking. During the last 50 years, the tobacco industry introduced new cigarettes or new design features to respond to these health concerns. These efforts claimed to reduce smokers' health risks by reducing exposure to cigarette toxins. The most prominent example is "Light" cigarettes. These so-called "low yield" cigarettes were marketed with implied or explicit claims about reduced health risks, intended to alleviate concerns about the harmful effects of smoking, ${ }^{4}$ and were promoted as an alternative to quitting. ${ }^{5}$ Believing at the time that Lights were likely to be less hazardous, the public health service and physicians, seeking to advise smokers, joined in recommending these low yield cigarettes to smokers. ${ }^{67}$ Light cigarettes became the dominant cigarette type, ${ }^{8}$ and many smokers were induced to switch to low yield cigarettes rather than quit. ${ }^{10}$

Review of tobacco documents has since revealed that the tobacco industry knew years ago that Light cigarettes were in fact unlikely to be any safer, but were nevertheless marketed as such to health concerned smokers. Recently, a court ruled that representations about Lights were intended to deceive smokers into believing that Lights were less harmful than regular cigarettes, that the tobacco industry was aware of the deception, and that the public health community was among those deceived by the misrepresentation. ${ }^{11}$ Indeed, recent research has demonstrated that low yield cigarettes are not substantially less hazardous than higher yield brands. ${ }^{8}{ }^{12}$ Thus, the introduction of Light cigarettes with implicit risk reduction claims probably exacerbated the disease burden caused by smoking. ${ }^{8}$

Now, the tobacco industry is again trying to address smokers' heightened health concerns by introducing modified tobacco products claiming reduced risk, and is seeking the endorsement of the public health, regulatory, and medical communities. The industry has recently introduced several "potentially reduced exposure products" or PREPs (as they are referred to in an Institute of Medicine report ${ }^{13}$ ), and more are likely to be introduced. PREPs are touted as a healthier alternative for smokers who are not ready or able to quit by reducing specific toxins found in tobacco smoke. Several PREPs have been test marketed, including Omni, ${ }^{14}$ Accord, ${ }^{15}$ and Eclipse. ${ }^{16}$

Eclipse exemplifies these products. Eclipse is a cigarettelike nicotine delivery device, marketed by RJ Reynolds Tobacco, in which tobacco is heated rather than burned. It resembles conventional cigarettes, but it differs in its heat source, filter, tobacco constituents, and composition of inhaled substances. ${ }^{17-19}$ The manufacturer claims Eclipse is toxicologically "cleaner" than conventional cigarettes, and makes explicit health claims about reductions in disease risks including "less risk of cancer", "less inflammation in the respiratory system", and "a lower risk of chronic bronchitis, possibly even emphysema." ${ }^{\prime 20}$ However, these claims have yet to be subjected to independent scientific or 
regulatory scrutiny. ${ }^{13}$ After being test marketed in Dallas and via the internet, Eclipse has begun national marketing. ${ }^{21}$

Toxicological and medical evaluation of the claims for reduced exposure and reduced risk from PREPs such as Eclipse is complex. ${ }^{13}$ However, concerns about PREPs go beyond their toxicological and health claims to their unintended consequences on the smoking population and thus on public health. ${ }^{13} 22$ First, PREPs may divert current smokers from quitting. Smokers may switch to Eclipse rather than quit if Eclipse is perceived as safer. Indeed, Eclipse advertising states that Eclipse is "the next best choice" to quitting. This advertising is reminiscent of early ads for a pivotal brand of Light cigarettes which stated: "Considering all I heard, I decided to either quit or smoke True ${ }^{\circledR}$. I smoke True ${ }^{\circledR \prime \prime} .{ }^{23}$ PREPs may also encourage resumption of smoking among ex-smokers, or even initiation by non-smokers.

To help shed light on the potential public health effects of PREPs, it is important to study smokers' and ex-smokers' perceptions of and reactions to PREPs. We report such an analysis. Taking Eclipse as an example of tobacco industry products marketed as PREPs, we conducted a national survey with current and ex-smokers to assess the impact of Eclipse's claims on the risk perception of Eclipse, stated intentions to purchase Eclipse, and interest in quitting (among smokers) and interest in resuming smoking with Eclipse (among exsmokers).

\section{METHODS}

\section{Participants}

A random digit dialled telephone survey was conducted in July 2000 with 1000 current cigarette smokers and 499 exsmokers (all ages 18 and older). Ex-smokers were oversampled to obtain 300 who quit smoking within the last two years; 199 had quit earlier. The telephone lists for sampling were generated by Scientific Telephone Samples (Foothill Ranch, California) to represent the continental USA. Regional quotas for interviews were assigned, based on state prevalence of cigarette smoking; the proportion of phone numbers sampled in each state was proportional to that state's estimated population of smokers. When a household was reached, a smoking respondent was selected at random for interview. The resulting data were weighted to match the demographics of US smokers and ex-smokers, respectively, as characterised in the 1997 National Health Interview Survey. ${ }^{24}$ Data for current daily smokers were weighted by sex, age, and race; only sex and age were used to weight the data for current occasional smokers and ex-smokers (that is, those who quit $<2$ years ago and those who quit $\geqslant 2$ years ago).

\section{Interview}

Separate interview scripts, with overlapping content, were used for smokers and ex-smokers. The interview initially assessed demographic and smoking history characteristics. Next, respondents were asked how concerned they were about eight different health risks of smoking, rated using a five point scale ranging from "very concerned" to "not at all concerned". Responses regarding concern about the health risks of smoking were averaged over four questions (that is, bronchitis and emphysema, heart disease, lung disease, lung cancer) that yielded a reliable estimate of subject's health concerns about smoking (Cronbach's $\alpha=0.88$ ). Besides providing an assessment of health concern, this introduced the health risks of smoking before introducing the PREP concept. Pilot work had suggested that the health claims for PREPs elicited complex reactions because they raised health concerns in the course of trying to reassure smokers; we aimed to assess the reassurance provided by PREP concepts once the concern had been raised.
After assessing smokers' interest in quitting, the interviewer described Eclipse to both smokers and ex-smokers, using language based on the manufacturer's descriptions: "I would like to ask you a few questions about a new brand of cigarettes on the market called Eclipse, which will soon be available everywhere. Eclipse contains far less of many of the compounds found in cigarette smoke that are believed to contribute to the risk of cancer and other illnesses. The makers of Eclipse say that the best choice for smokers is to quit, but that Eclipse is the next best choice." The interviewer then exposed respondents to both health and aesthetic claims about Eclipse similar to those found in Eclipse advertisingfor example, "may present less risk of cancer," "contains far less of many of the compounds found in cigarette smoke that are believed to contribute to the risk of cancer and other illnesses", "reduces secondhand smoke by $80 \%$ ", "leaves no messy ashes".

Respondents were then asked about: (1) the perceived risk of Eclipse, evaluated by rating its risk on a 0-10 scale, where 0 referred to "not smoking_-all health risk eliminated" and 10 referred to the risk of smoking regular cigarettes; (2) the perceived risk of Light and Ultra Light cigarettes, evaluated similarly; (3) how likely participants would be to buy Eclipse; and (4) how participants perceived the effect of Eclipse on future quitting (for smokers) or the resumption of smoking (for ex-smokers). Finally, smokers' interest in quitting was re-assessed.

Current smokers' interest in quitting was assessed before and after exposure to the description of Eclipse using five questions: (1) "planning to quit smoking in the next 30 days" (yes/no); (2) "seriously considering quitting smoking in the next six months" (yes/no); (3) overall interest in quitting ( 10 point scale ranging from "not at all interested" to "extremely interested"); (4) likelihood of trying to quit smoking in the next year (five-point scale ranging from "very likely" to "very unlikely"); and (5) self selection into one of five categories of the contemplation ladder ${ }^{25}$ : "I'm taking action to quit such as cutting down or enrolling in a program", "I'm starting to think about how to change my smoking patterns", "I think I should quit but I'm not quite ready", "I think I need to consider quitting someday", or "I have no thoughts of quitting". The first two questions allowed smokers to be classified into three groups representing stages of readiness to quit based on the stages of change framework ${ }^{26}$ : preparation $(\mathrm{Q} 1=$ yes $), \quad$ contemplation $(\mathrm{Q} 2=$ yes $)$, and precontemplation $(\mathrm{Q} 2=\text { no })^{*}$. This classification predicts subsequent quitting behaviour. ${ }^{27}$ Additionally, we assessed the quit index reported by Shiffman et al, ${ }^{10}$ which was scored as follows: $6=\mathrm{Q} 1$ is "yes"; $5=\mathrm{Q} 2$ is "yes"; $4=\mathrm{Q} 4 \geqslant 3 ; 3=\mathrm{Q} 3 \geqslant 5 ; 2=\mathrm{Q} 5$ $\geqslant 2 ; 1=$ Q5 is 1 .

\section{Data analysis}

Outcome measures were evaluated for differences by demographic characteristics. $\alpha$ of 0.05 was used with no adjustments for multiplicity. Data analyses were performed appropriate to the data (that is, continuous outcomes: Student's $t$ test for independent groups; categorical outcomes: McNemar's test and Bowker's test of symmetry for change, and Pearson $\chi^{2}$ and logistic regression for independent groups) using SAS version 8.2 for Windows.

\section{RESULTS}

The sample characteristics (table 1) were comparable to US smokers and ex-smokers, respectively, in the 1997 National Health Interview Survey. ${ }^{24}$

*We did not include quitting in the past year in the classification, as we were interested in assessing change, and history cannot be changed. 
Table 1 Demographic and smoking characteristics of the sample

\begin{tabular}{|c|c|c|}
\hline & Smokers & Ex-smokers \\
\hline & $(n=1000)$ & $(n=499)$ \\
\hline$\%$ male & $53.1 \%$ & $54.7 \%$ \\
\hline Age & $40.4(14.0)$ & $44.5(17.0)$ \\
\hline Race & & \\
\hline White & $78.3 \%$ & $81.7 \%$ \\
\hline Black & $10.2 \%$ & $8.6 \%$ \\
\hline Hispanic & $6.5 \%$ & $7.2 \%$ \\
\hline Other & $5.1 \%$ & $2.6 \%$ \\
\hline Education & & \\
\hline$\leqslant$ High school & $51.9 \%$ & $36.2 \%$ \\
\hline At least some college & $48.1 \%$ & $63.8 \%$ \\
\hline Income & & \\
\hline$<\$ 50000$ & $46.1 \%$ & $34.1 \%$ \\
\hline$\geqslant \$ 50000$ & $53.9 \%$ & $65.9 \%$ \\
\hline Cigareftes per day & $18.9(11.8)$ & $20.8(14.5)^{*}$ \\
\hline Time to first cigarette of $d$ & & \\
\hline Within 5 minutes & $26.0 \%$ & NA \\
\hline 6-30 minutes & $33.3 \%$ & \\
\hline$>30$ minutes & $40.7 \%$ & \\
\hline Type of cigarette & & \\
\hline Regular & $44.5 \%$ & $56.6 \% \dagger$ \\
\hline Light & $40.4 \%$ & $34.1 \%$ \\
\hline Ultra Light & $15.2 \%$ & $9.3 \%$ \\
\hline Years smoking & $18.3(12.8)$ & $14.5(12.3) \dagger$ \\
\hline Stage of change & & \\
\hline Precontemplation & $48.6 \%$ & NA \\
\hline Contemplation & $32.9 \%$ & \\
\hline Preparation & $18.5 \%$ & \\
\hline Health concern $\ddagger$ & $3.8(1.2)$ & $3.6(1.3)$ \\
\hline
\end{tabular}

Data are presented as percentages or mean (SD).

*At time of cessation.

†Before cessation.

$\ddagger$ Average concern about the health risks of smoking (that is, bronchitis and emphysema, heart disease, lung disease, and lung cancer).

NA, not applicable

\section{Current smokers}

Perceived health risks of eclipse

Almost all current smokers (91.4\%) thought Eclipse was safer than Regular cigarettes (that is, "risk" values less than 10). Moreover, as shown in fig 1, almost a quarter $(23.9 \%)$ considered Eclipse to be completely safe (that is, 0 , equivalent to not smoking at all). On average, participants expected that Eclipse would reduce smoking risk by $62.1 \% \quad(31.2) \%$ compared to regular cigarettes, with three quarters $(75.9 \%)$ expecting that Eclipse would reduce health risks by at least $50 \%$. Eclipse was also regarded as significantly safer than current Light (McNemar's test $(1)=109.58 ; \mathrm{p}<0.001$ ) or Ultra Light (McNemar's test $(1)=87.79 ; \mathrm{p}<0.001$ ) cigarettes. Compared to the $23.9 \%$ who regarded Eclipse as completely safe, only $9.4 \%$ and $11.3 \%$ regarded Lights and Ultra Lights, respectively, as completely safe.

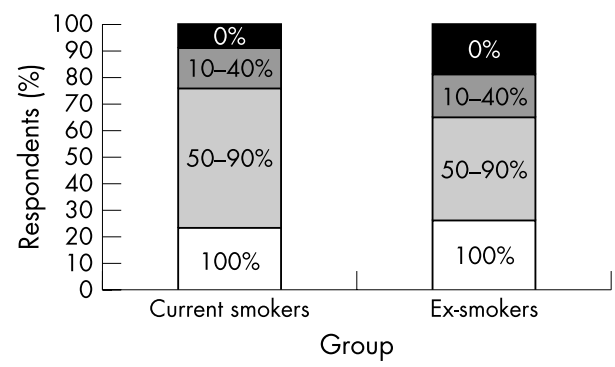

Figure 1 Percentage of current smokers and ex-smokers who believed Eclipse reduced health risk by $0 \%$ (not at all), $10-40 \%, 50-90 \%$ or $100 \%$ (completely eliminated risk). Based on responses to a question characterising risk of Eclipse as ranging from 0 (risk of not smoking) to 10 (same as risk of a regular cigarette).
Smokers' perception of Eclipse's health risk varied significantly with the smoker's demographic characteristics (table 2). The view that Eclipse was completely safe was more likely to be held by women, older smokers, non-whites, those with less education, and those having less overall concern about smoking effects on their health. No other respondent characteristics were related to the perceived health risks of Eclipse.

\section{Interest in purchasing Eclipse}

As shown in fig 2 and table 3, Eclipse appealed to most smokers: $57.4 \%$ said they were "somewhat likely" or "very likely" to purchase Eclipse within the next six months. Eclipse appealed equally to men and women, to older and younger smokers, and whites and non-whites, but was more appealing to those who were less dependent (that is, those who reported a longer time to the first cigarette of day) and those having greater concern about the health effects of smoking. In addition, those who currently smoke Ultra Light cigarettes expressed greater interest in Eclipse than did smokers of regular or Light cigarettes. Surprisingly, interest in purchasing Eclipse was not higher among smokers who perceived Eclipse to be safer than regular cigarettes (table 3). This was true even when considering respondents' degree of health concern (via an interaction between health concern and safety evaluation; $\chi^{2}(1)=1.85, \mathrm{p}=\mathrm{ns}$ ).

Smokers' interest in Eclipse varied with smokers' interest in quitting (fig 2). Interest in Eclipse was lowest among those who were in preparation for quitting within 30 days, followed by precontemplation smokers not interested in quitting. Interest in Eclipse was highest among those contemplating quitting within six months.

Effects of the Eclipse concept on interest in quitting We asked respondents whether they thought that hearing about Eclipse had influenced their interest in quitting. About equal numbers envisioned increased interest (19.7\%) and diminished interest $(20.0 \%)$, but most envisioned unchanged interest in quitting $(60.3 \%)$. We also assessed the impact of exposure to Eclipse claims more directly by contrasting smokers' stated interest in quitting when assessed after versus before exposure to the Eclipse concept. The quit index showed no change (mean change $=-0.034, \mathrm{SD}=1.13$, $\underline{\mathrm{t}}(999)=0.94, \mathrm{p}<0.346)$. However, the stages of change assessment painted a different picture, as seen in fig 3 . While most smokers $(81.7 \%)$ remained in the same stage of change after being exposed to Eclipse information, $11.0 \%$ showed reduced interest in quitting, and only $7.3 \%$ demonstrated increased interest. Thus, there was a significant net loss of interest in quitting (Bowker's test of symmetry $(3)=10.31$; $p<0.017)$. The loss of interest in quitting was particularly notable among those initially contemplating quitting in the next six months; nearly a quarter $(21.4 \%)$ lost interest in quitting after hearing about Eclipse. It is also notable that more than $10 \%$ of those who initially indicated they were preparing to quit smoking within 30 days subsequently reported that they were not even contemplating quitting in the next six months.

\section{Ex-smokers}

\section{Perceptions of Eclipse}

Among ex-smokers, $81.3 \%$ thought Eclipse was safer than regular cigarettes and $26.2 \%$ considered Eclipse to be completely safe (that is, equivalent to not smoking at all; fig 1 and table 2 ). The average (SD) perceived risk reduction was $55.3 \%(37.4) \%$, with $64.9 \%$ of ex-smokers believing that Eclipse reduced health risks by at least $50 \%$. There was no difference between recent and long term quitters on average perceived risk reduction $(\mathrm{t}(466)=0.02, \mathrm{p}<0.985)$. 
Table 2 Perceived health risks of Eclipse

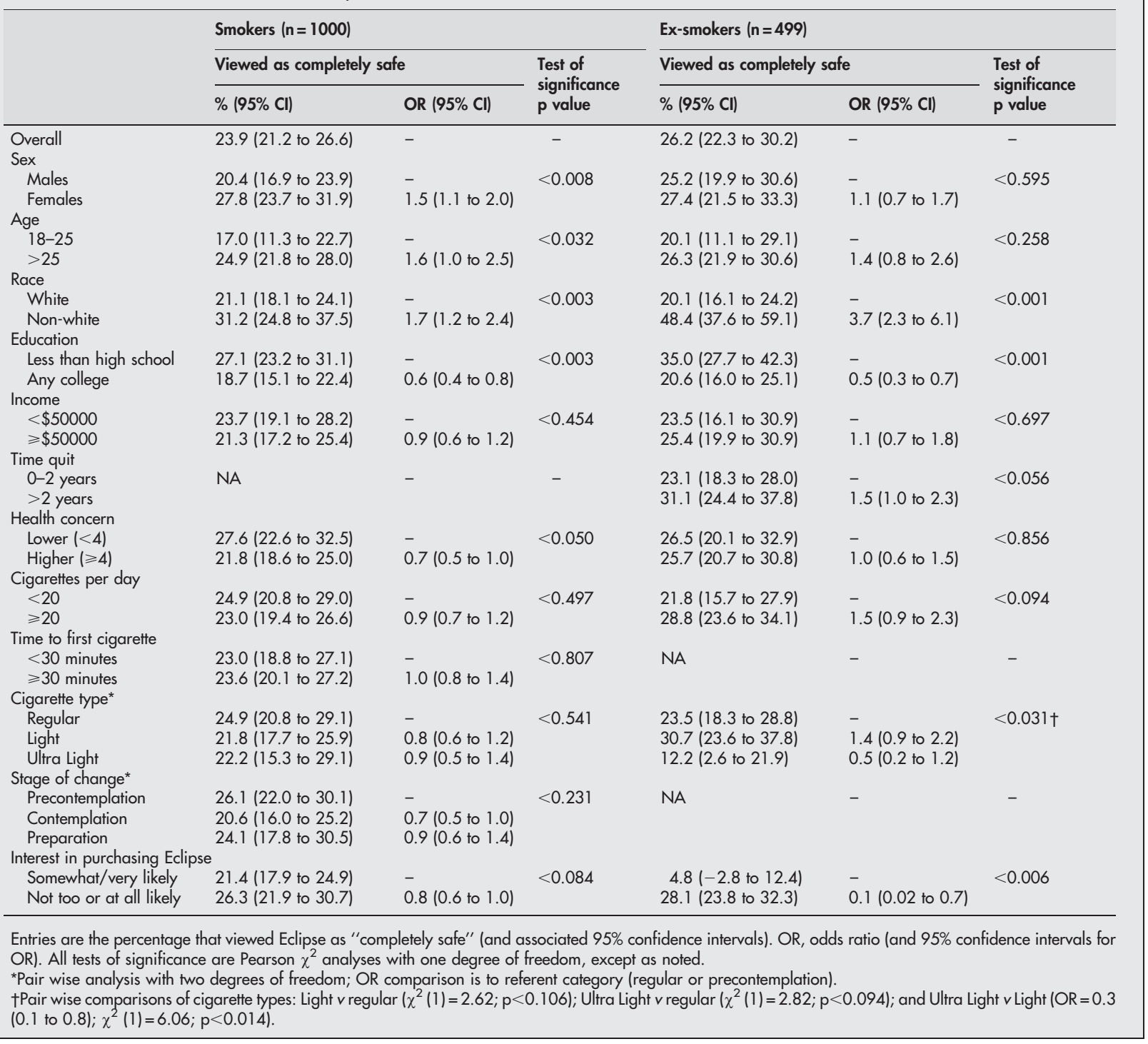

Ex-smokers also regarded Eclipse as significantly safer than Light (McNemar's test $(1)=20.87 ; \mathrm{p}<0.001)$ or Ultra Light $($ McNemar's test $(1)=16.47 ; \mathrm{p}<0.001)$ cigarettes. Compared to the $26.2 \%$ who regarded Eclipse as completely safe, $20.4 \%$ and $22.0 \%$ regarded Lights and Ultra Lights, respectively, as completely safe. There were no differences between long term and recent ex-smokers in perceptions of Eclipse versus Light or Ultra Light cigarettes.

Non-whites and those with less education were significantly more likely to believe Eclipse was completely safe. In addition, ex-smokers who had smoked Light cigarettes were more likely to view Eclipse as completely safe than those who had not smoked Ultra Light cigarettes, but ex-smokers of regular cigarettes were not. No other demographic characteristics influenced beliefs about Eclipse safety.

\section{Interest in purchasing Eclipse}

As shown in table 3, few ex-smokers (6.2\%) said they were "somewhat likely" or "very likely" to purchase or adopt Eclipse within six months. Interest was significantly higher among non-whites. Most prominently, likelihood of adopting Eclipse was more than three times higher among young adults (18-25 years) than among older adults. No other demographic characteristics exhibited associations with Eclipse appeal.

We compared interest in Eclipse among recent quitters versus long term quitters. Recent quitters were significantly more interested in Eclipse (8.9\% v 2.0\%) (table 3). However, this effect was significantly moderated by and confounded with age, as there were very few young adults $(2 \%)$ who had quit more than two years ago. Among ex-smokers who had quit within the last two years, young adults (18-25 years) were significantly more interested in Eclipse, compared to adults over $25\left(15.2 \%\right.$ v 6.4\%; $\left.\chi^{2}(1)=5.38, \mathrm{p}<0.021\right)$ (fig 4). Among the older adults, interest in Eclipse was significantly higher for the recent quitters $(6.4 \% \vee 2.1 \%$; $\left.\chi^{2}(1)=4.35, p<0.038\right)$. Finally, interest in Eclipse purchase was not influenced by perceived Eclipse safety $\left(\chi^{2}(1)=0.81, p=n s\right)$, even when considering respondents' degree of health concern (interaction: $\chi^{2}(1)=0.64$, $\mathrm{p}=\mathrm{ns})$.

\section{Effects of the Eclipse concept on interest in resuming smoking}

Besides assessing ex-smokers' interest in using Eclipse (which implies returning to smoking), we also asked 


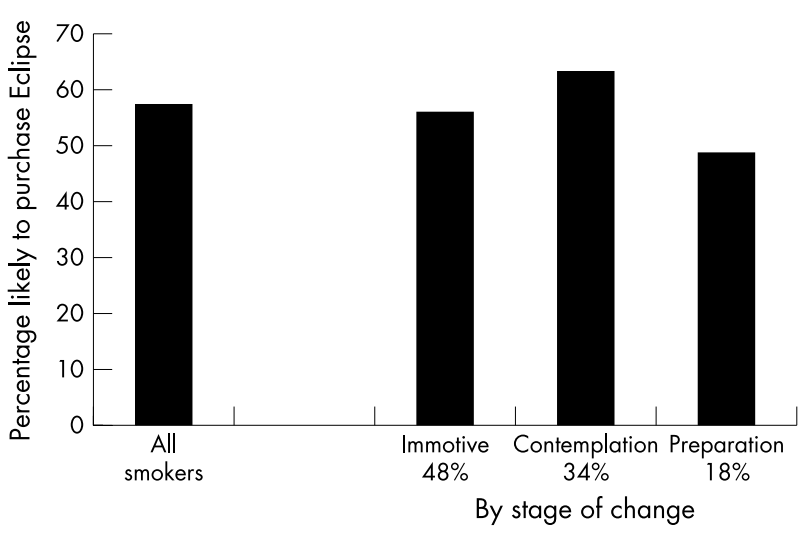

Figure 2 Percentage of current smokers who said they were "somewhat likely" or "very likely" to purchase Eclipse within the next six months. Data are also shown by current stage of change, where Preparation indicates plan to quit in the next 30 days, Contemplation indicates thinking about quitting in the next six months, and Immotive indicates not thinking about quitting in the next six months. Percentages under the stage labels indicate the percentage of smokers who were in each stage. Smokers in contemplation were significantly more likely to express an interest in Eclipse.

ex-smokers whether they thought Eclipse claims affected their interest in resumption of smoking. Almost all exsmokers $(74.9 \%)$ reported either no change in their interest in starting to smoke again or diminished interest $(21.5 \%)$, with only a small percentage exhibiting an increased interest (3.6\%). Recent ex-smokers (within the last two years) were three times more likely to indicate increased interest in resumption of smoking compared to long term ex-smokers; however, this difference was not significant $(4.9 \% \vee 1.6 \%$, respectively; $\left.\chi^{2}(1)=3.77, \mathrm{p}<0.153\right)$. There was no association between stated likelihood of adopting Eclipse and ex-smokers' statements of whether Eclipse would change their interest in smoking $\left(\chi^{2} \quad(1)=3.70\right.$, $\mathrm{p}<0.158)$, suggesting that ex-smokers did not equate use of Eclipse with resumption of smoking.

\section{DISCUSSION}

The introduction of tobacco products claiming reduced health risk has raised the issue of how such products and their claims might be viewed by smokers and ex-smokers. This is, to our knowledge, the first study to assess this question in both smokers and ex-smokers.

We tested claims made for Eclipse, a cigarette product currently being marketed with claims of reduced risk, which we took as an exemplar of such products. These results indicate that smokers substantially overestimate the reduction in risk likely to be afforded by products such as Eclipse. After being exposed to statements about Eclipse reflecting the claims made by RJ Reynolds, almost a quarter of all smokers concluded that smoking Eclipse held no risk whatsoever, characterising smoking Eclipse as no different than not smoking at all (even RJ Reynolds does not claim this for Eclipse). Although we did not find this effect in the survey, it seems plausible that smokers (and non-smokers) who perceive the product as being totally safe may take up the new product instead of quitting or-in the case of exsmokers-remaining abstinent. Even among those who considered Eclipse to have some risk, the expected reductions in risk were quite optimistic, with many smokers expecting health benefits that went well beyond even the claims made for the product by its manufacturer. This highlights the importance of understanding how smokers interpret claims made for PREP products, rather than just the literal statements made in the promotional claims.

Quitting smoking completely is the best protection against tobacco related morbidity and mortality, ${ }^{13}$ and should continue to be the first line recommendation for those who can quit. Accordingly, to maximise public health benefit, a PREP should ideally appeal most to smokers who have little interest in quitting. However, while Eclipse held lower appeal to smokers who were preparing to quit within 30 days, its peak appeal was to the smokers who were contemplating quitting within six months. Interest in Eclipse was lower among those who were not interested in quitting-the ones most likely to benefit from reduced risk smoking. This suggests that the appeal of Eclipse and similar PREPs may be misdirected, and likely to divert smokers from quitting.

While exposure to the Eclipse concept and claims during the course of the survey was brief, pre- and post-exposure assessment of their interest in quitting nevertheless showed movement away from quitting. Even though the smokers themselves did not think their interest in quitting had been affected, and one measure of quit interest showed no change, there was a net decrease of $19 \%$ in smokers who were contemplating quitting within six months. This suggests that becoming aware of products claiming reduced risk can diminish smokers' interest in quitting, thus diverting smokers from the most effective risk reduction strategy. This parallels the experience with the marketing of Light cigarettes, which is thought to have diverted smokers from quitting by offering them a reassuring but false "safe haven" from the risks of smoking, and thus blunted the effect of health campaigns promoting quitting. ${ }^{8}$

Among adult ex-smokers, $6 \%$ of recent quitters and 2\% of long term quitters expressed interest in resuming smoking with Eclipse. While these percentages are modest, they potentially represent a large public health impact, as there are 44.7 million ex-smokers in the US adult population. ${ }^{1}$ If even a small percentage of these ex-smokers are lured back to smoking by such products, this would substantially erode hard won gains for tobacco control. Importantly, Eclipse and other PREPs can only increase risk for ex-smokers, since they have already stopped using tobacco. The finding of some interest in Eclipse by ex-smokers confirms the suggestion ${ }^{13} 22$ that we must consider appeal to ex-smokers when evaluating the population impact of PREPs.

Among ex-smokers, the highest level of interest was seen in young adults (18-25 years) who had stopped smoking within the past two years. Many youth experiment with smoking, but stop smoking before progressing to regular smoking, which often leads to life long addiction. The fact that $15 \%$ of the young adults who had recently given up smoking were interested in buying Eclipse suggests that the offer of "safe cigarettes" might undermine efforts to prevent adoption of smoking in youth, leading to increased morbidity and mortality years from now. We did not evaluate the appeal of PREPs among youth who were not yet smoking, but the data suggest the possibility that the promise of "safe smoking" could induce more people to initiate smoking.

Our study was subject to several limitations. The communication of Eclipse claims was modelled after claims made by its manufacturer on its website. However, having an unknown interviewer read plain text is not an adequate model for the sort of public relations and advertising campaign that would accompany a full product launch. Moreover, we studied a single brief exposure to the claims over a period of a few minutes, whereas a PREP product launch and marketing campaign would result in multiple exposures over months and years. Repeated exposure to reduced risk claims might be especially important, because the claims incorporate an implicit reminder that smoking is 
Table 3 Interest in purchasing Eclipse

\begin{tabular}{|c|c|c|c|c|c|c|}
\hline & \multicolumn{3}{|l|}{ Smokers $(n=1000)$} & \multicolumn{3}{|l|}{ Ex-smokers $(n=499)$} \\
\hline & \multicolumn{2}{|c|}{ Somewhat or very likely to purchase } & \multirow{2}{*}{$\begin{array}{l}\text { Test of } \\
\text { significance } \\
\text { p value }\end{array}$} & \multicolumn{2}{|c|}{ Somewhat or very likely to purchase } & \multirow{2}{*}{$\begin{array}{l}\text { Test of } \\
\text { significance } \\
\text { p value }\end{array}$} \\
\hline & $\%(95 \% \mathrm{Cl})$ & OR $(95 \% \mathrm{Cl})$ & & $\%(95 \% \mathrm{Cl})$ & OR $(95 \% \mathrm{Cl})$ & \\
\hline Overall & $57.4(54.2$ to 60.5$)$ & - & - & $6.2(4.0$ to 8.3$)$ & - & - \\
\hline \multicolumn{7}{|l|}{ Sex } \\
\hline Males & $57.0(52.7$ to 61.2$)$ & - $\quad$ - & $<0.789$ & $6.9(3.8$ to 9.9$)$ & - & $<0.464$ \\
\hline Females & $57.8(53.2$ to 62.4$)$ & $1.0(0.8$ to 1.3$)$ & & $5.3(2.4$ to 8.2$)$ & $0.8(0.4$ to 1.6$)$ & \\
\hline \multicolumn{7}{|l|}{ Age } \\
\hline $18-25$ & $53.1(45.4$ to 60.8$)$ & - & $<0.084$ & $14.4(6.8$ to 22.1$)$ & - & $<0.001$ \\
\hline$>25$ & $60.5(57.0$ to 64.0$)$ & $1.4(1.0$ to 1.9$)$ & & $4.4(2.4$ to 6.4$)$ & $0.3(0.1$ to 0.6$)$ & \\
\hline \multicolumn{7}{|l|}{ Race } \\
\hline White & 57.0 (53.4 to 60.7$)$ & - $\quad 1 \quad-1$ & $<0.438$ & 5.3 (3.0 to 7.5$)$ & - & $<0.039$ \\
\hline Non-white & $60.1(53.3$ to 66.9$)$ & $1.1(0.8$ to 1.6$)$ & & $11.2(4.6$ to 17.8$)$ & $2.3(1.0$ to 5.1$)$ & \\
\hline \multicolumn{7}{|l|}{ Education } \\
\hline Less than high school & $59.2(54.8$ to 63.6$)$ & - & $<0.618$ & $7.6(3.7$ to 11.5$)$ & - & $<0.329$ \\
\hline Any college & 57.6 (53.0 to 62.2$)$ & $0.9(0.7$ to 1.2$)$ & & $5.4(2.9$ to 7.9$)$ & $0.7(0.3$ to 1.5$)$ & \\
\hline \multicolumn{7}{|l|}{ Income } \\
\hline$<\$ 50000$ & $62.0(56.8$ to 67.2$)$ & - $\quad 1 \quad-1$ & $<0.212$ & $5.8(1.7$ to 9.8$)$ & - & $<0.658$ \\
\hline$\geqslant \$ 50000$ & $57.4(52.4$ to 62.4$)$ & $0.8(0.6$ to 1.1$)$ & & $7.0(3.8$ to 10.1$)$ & $1.2(0.5$ to 3.0$)$ & \\
\hline \multicolumn{7}{|l|}{ Time quit } \\
\hline $0-2$ years & NA & - & - & $8.9(5.7$ to 12.2$)$ & - & $<0.002$ \\
\hline$>2$ years & & & & $2.0(0.1$ to 4.0$)$ & $0.2(0.1$ to 0.6$)$ & \\
\hline \multicolumn{7}{|l|}{ Health concern } \\
\hline Lower $(<4)$ & 47.7 (42.1 to 53.2 ) & - & $<0.001$ & 6.3 (2.9 to 9.7$)$ & - & $<0.746$ \\
\hline Higher ( $\geqslant 4)$ & $62.2(58.5$ to 66.0$)$ & 1.8 (1.4 to 2.4$)$ & & $5.6(3.1$ to 8.3$)$ & $0.9(0.4$ to 1.9$)$ & \\
\hline \multicolumn{7}{|l|}{ Cigarettes per day } \\
\hline$<20$ & 55.6 (50.8 to 60.3$)$ & - & $<0.326$ & $6.6(3.0$ to 10.2$)$ & - & $<0.703$ \\
\hline$\geqslant 20$ & $58.7(54.5$ to 62.9$)$ & $1.1(0.9$ to 1.5$)$ & & $5.7(3.1$ to 8.3$)$ & $0.9(0.4$ to 1.8$)$ & \\
\hline \multicolumn{7}{|l|}{ Time to first cigarette } \\
\hline$<30$ minutes & 53.5 (48.5 to 58.4$)$ & - & $<0.043$ & NA & - & - \\
\hline$\geqslant 30$ minutes & 60.1 (56.0 to 64.2 ) & $1.3(1.0$ to 1.7$)$ & & & & \\
\hline \multicolumn{7}{|l|}{ Cigarette type* } \\
\hline Regular & 52.1 (47.3 to 56.9 ) & - & $<0.001 \dagger$ & $5.2(2.5$ to 7.8$)$ & - & $<0.557$ \\
\hline Light & $58.0(53.0$ to 69.9$)$ & $1.3(1.0$ to 1.7$)$ & & $6.7(2.9$ to 10.5$)$ & $1.3(0.6$ to 3.0$)$ & \\
\hline Ultra Light & 70.5 (62.8 to 78.3 ) & $2.2(1.4$ to 3.4$)$ & & $9.1(0.3$ to 17.9$)$ & $1.8(0.6$ to 6.1$)$ & \\
\hline \multicolumn{7}{|l|}{ Stage of change ${ }^{*}$} \\
\hline Precontemplation & 55.9 (51.2 to 60.9$)$ & - & $<0.008 \ddagger$ & NA & - & - \\
\hline Contemplation & 63.3 (57.9 to 68.7 ) & $1.3(1.0$ to 1.8$)$ & & & & \\
\hline Preparation & 48.7 (41.1 to 56.4$)$ & $0.7(0.5$ to 1.0$)$ & & & & \\
\hline \multicolumn{7}{|l|}{ Perceived risk of Eclipse } \\
\hline View as completely safe & 52.9 (46.2 to 59.5$)$ & - & $<0.084$ & $1.2(-0.7$ to 3.1$)$ & - & $<0.006$ \\
\hline Not completely safe & 59.5 (55.9 to 63.1$)$ & $0.8(0.6$ to 1.0$)$ & & 8.5 (5.5 to 11.4 ) & $0.1(0.02$ to 0.7$)$ & \\
\hline
\end{tabular}

Entries are the percentage that were "somewhat" or "very likely" to purchase Eclipse (and associated 95\% confidence intervals). OR, odds ratio (and $95 \%$ confidence intervals for OR). All tests of significance are Pearson $\chi^{2}$ analyses with one degree of freedom, except as noted.

*Pair wise analysis with two degrees of freedom; OR comparison is to referent category (regular or precontemplation).

†Pair wise comparisons of cigarette types: Light $v$ regular $\left(\chi^{2}(1)=2.82 ; p<0.094\right)$; Ultra Light $v$ regular $\left(\chi^{2}(1)=13.98 ; p<0.001\right)$; and Ultra Light $v$ Light $\left(\mathrm{OR}=1.7(1.1\right.$ to 2.7$\left.) ; \chi^{2}(1)=6.56 ; p<0.011\right)$.

‡Pair wise comparisons of stage of change: contemplation $v$ precontemplation $\left(\chi^{2}(1)=3.64 ; p<0.057\right)$; preparation $v$ precontemplation $\left(\chi^{2}(1)=2.98\right.$; $\mathrm{p}<0.085)$; and preparation $v$ contemplation (OR=0.6 $(0.4$ to 0.8$\left.) ; \chi^{2}(1)=9.39 ; p<0.003\right)$.

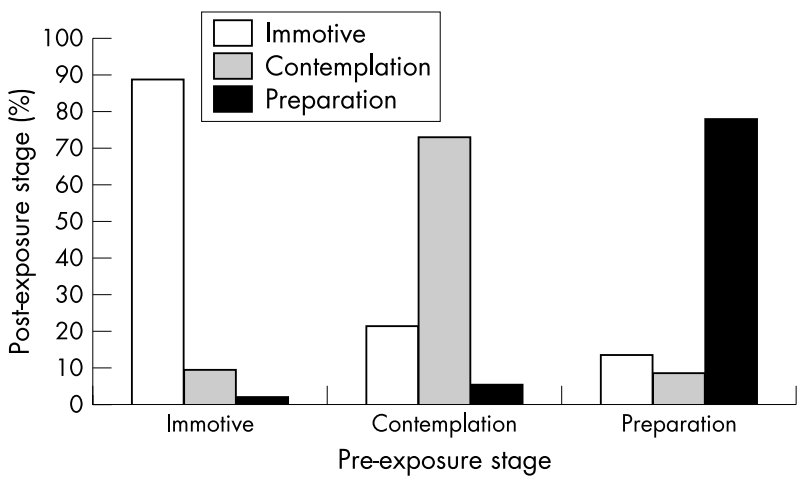

Figure 3 Shifts in interest in quitting, expressed as stages of change, from before to after exposure to the Eclipse concept and claims. Preparation indicates plan to quit in the next 30 days, Contemplation indicates thinking about quitting in the next six months, and Immotive indicates not thinking about quitting in the next six months. There was a significant downward shift in stage of change, most notably among smokers who were initially in contemplation. 


\section{What this paper adds}

Tobacco companies are introducing products that claim to reduce the hazard of smoking. Smokers' beliefs about such products, and their impact on interest in quitting, have not been assessed.

The study shows that many smokers exaggerate the safety of a "reduced-risk" cigarette-a quarter believe it is completely safe. Interest in reduced risk cigarettes is greatest among smokers contemplating quitting, and hearing about the product diminishes smokers' interest in quitting. Young adult ex-smokers who had stopped smoking within the last two years also showed interest in adopting reduced risk cigarettes. The findings suggest that marketing of such products may mislead smokers and undermine cessation and prevention.

hazardous, which can increase health concern even while aiming to reduce it. Over time, smokers might habituate to this "hazard" message, and thus become more responsive to the reassuring "safety" message. Further, different effects may emerge when people are exposed to multiple marketing messages for diverse products. Thus, we did not adequately model the impact of introducing multiple PREPs to the market. Our assessment probably underestimated the impact of health claims for a PREP product. In any case, this study examined smoker's and ex-smokers' stated attitudes, beliefs, and intentions. Studies examining actual behaviour-purchase and use of Eclipse, and attempts to quit-are sorely needed.

We only assessed stated interest in quitting, which may be overstated, and not actual smoking cessation. Respondents may have been reluctant to admit to lack of interest in quitting or to diminished interest in quitting in the pre-post assessment, or may have felt constrained to be consistent with their prior answers. Thus, the study may underestimate changes in attitudes about quitting. Finally, our findings are, strictly speaking, limited to the product and claims we evaluated in the study. Different PREPs and different claims could change the effect.

The results suggest the need for caution in estimating the impact of tobacco products claiming reduced risk. It seems clear that some smokers and ex-smokers will overestimate the protection (if any) afforded by these new products and be drawn to a "safe cigarette". Our results suggest this could result in reduced interest in quitting among smokers and increased interest in resuming smoking among ex-smokers. Even if the toxicological claims made by the manufacturers of PREPs were valid, the resulting increase in smoking prevalence could result in increased, rather than decreased, population morbidity and mortality. Thus, the public health and physician community needs to exercise caution in supporting products claiming reduced risk to avoid repeating the errors made in promoting Light cigarettes. These issues highlight the urgent need for regulation of tobacco products, especially those claiming reduced health risks.

\section{ACKNOWLEDGEMENTS AND FINANCIAL DISCLOSURE}

This study was supported by GlaxoSmithKline Consumer Healthcare which markets nicotine replacement medications for smoking cessation.

Drs Shiffman and Pillitteri and Mr Di Marino serve as consultants to GSKCH on an exclusive basis regarding matters relating to smoking cessation. Dr Shiffman also has a financial interest in a venture to develop a new nicotine replacement medication.
Mr Burton is Vice President, Smoking Control, Strategic Development, and Switch for GlaxoSmithKline Consumer Healthcare, LP.

We wish to thank Mitchell Zeller for providing insightful comments on an earlier version of this manuscript.

\section{Authors' affiliations}

S Shiffman, Pinney Associates and University of Pittsburgh, Pittsburgh, Pennsylvania, USA

J L Pillitteri, Pinney Associates, Seattle, Washington, USA

S L Burton, GlaxoSmithKline Consumer Healthcare, Pittsburgh, Pennsylvania, USA

M E Di Marino, Pinney Associates, Bethesda, Maryland, USA

\section{REFERENCES}

1 Centers for Disease Control. Cigarette smoking among adults - United States, 2001. MMWR Morb Mortal Wkly Rep 2003;52:953-6.

2 Centers for Disease Control. Annual smoking-attributable mortality, years of potential life lost, and economic costs-United States, 1995-1999. MMWR Morb Moral Wkly Rep 2002;51:300-3.

3 World Health Organization. World Health Report 2002. Geneva: WHO, 2002. http://www.who.int/whr/2002.

4 Warner KE, Slade J. Low tar, high toll. Am J Pub Health 1992;82:17-18.

5 Hurt RD, Robertson CR. Prying open the door to the tobacco industry's secrets about nicotine: The Minnesota tobacco trial. JAMA 1998;280:1173-81.

6 Shopland DR. Historical perspective: the low tar lie. Tobacco Control 2001; 10(suppl I):i1-i3.

7 US Department of Health and Human Services. The health consequences of smoking: the changing cigarette. A report of the Surgeon General, 1981. Rockville, Maryland: Public Health Service, Office of the Assistant Secretary for Health, Office on Smoking and Health, 1981. (DHHS Publication No (PHS) 81-50156.)

8 National Cancer Institute. Risks associated with smoking cigarettes with low machine-measured yields of tar and nicotine, Smoking and Tobacco Control Monograph 13. Bethesda, Maryland: US Department of Health and Human Services, National Cancer Institute, October, 2001.

9 Giovino GA, Tomar SL, Reddy MN, et al. Attitudes, knowledge, and beliefs about low-yield cigarettes among adolescents and adults. In: The FTC cigarette test method for determining tar, nicotine, and carbon monoxide yields of US cigarettes: report of the NCl Expert Committee. Bethesda, Maryland: National Institutes of Health, National Cancer Institute, 1996. (NIH Publication No 964028.):39-53.

10 Shiffman S, Pillitteri JL, Burton SL, et al. Smokers' beliefs about "Light" and "Ultra Light" cigarettes. Tobacco Control 2001;10(suppl I):i17-i23.

11 Miles v. Philip Morris. Case No. 00-L-112. Madison County, Illinois: Third Judicial Circuit, 2003

12 Thun MJ, Burns DM. Health impact of "reduced yield" cigarettes: a critical assessment of the epidemiological evidence. Tobacco Control 2001;10(suppl I):i4-i1 1.

13 Stratton K, Shetty P, Wallace R, et al. Clearing the smoke: assessing the science base for tobacco harm reduction. Washington DC: National Academy Press, 2001.

14 Knox A. Nicotine-free tobacco product opposed by industry, health advocates. The Philadelphia Inquirer 2001 April 16.

15 Blackwell JR. Researchers say users of Philip Morris device may smoke more. Richmond Times-Dispatch (Virginia) 2000 August 17.

16 Weiss R. RJR to heavily market new cigarette. Washington Post 2000 April 19.

17 Benowitz NL, Jacob P, Slade J, et al. Nicotine content of the Eclipse nicotine delivery device. Am J Public Health 1997;87:1865-6.

18 Pauly JL, Streck RJ, Cummings KM. US patents shed light on Eclipse and future cigarettes. Tobacco Control 1995;4:261-5.

19 Slade J. Innovative nicotine delivery devices from tobacco companies. In: Ferrence R, Slade J, Room R, Pope M, eds. Nicotine and public health. Washington DC: American Public Health Association, 2000:209-28.

20 RJ Reynolds Tobacco. Eclipse product online, Dec 2002. http:// www.eclipse.rirt.com.

21 Schlisserman C. RJ Reynolds to ship 'safer' cigarette nationally in April. Bloomberg News 2003 March 8.

22 Shiffman S, Gitchell JG, Warner KE, et al. Tobacco harm reduction: conceptual structure and nomenclature for analysis and research. Nicotine Tob Res 2002:S113, 29.

23 Pollay RW, Dewhirst T. Marketing cigarettes with low machine-measured yields. In: Risks associated with smoking cigarettes with low machinemeasured yields of tar and nicotine, Smoking and Tobacco Control Monograph 13. Bethesda, Maryland: US Department of Health and Human Services, National Cancer Institute, October 2001:199-235.

24 National Center for Health Statistics. Data from the National Health Interview Survey. Hyattsville, Maryland: Public Health Service, 1997.

25 Biener L, Abrams DB. The contemplation ladder: validation of a measure of readiness to consider smoking cessation. Health Psych 1991;10:360-5.

26 DiClemente CC, Prochaska JO, Fairhurst SK, et al. The process of smoking cessation: an analysis of precontemplation, contemplation, and preparation stages of change. J Consult Clin Psychol 1991;59:295-304.

27 Ward KD, Klesges RC, Halpern MT. Predictors of smoking cessation and stateof-the-art smoking interventions. Journal of Social Issues 1997;53:129-45. 